Article

\title{
Porosity prediction from gravity inversion with constraints from resistivity data
}

\author{
Fernando A. Monteiro Santos ${ }^{1^{*}}$ and Patrícia Represas ${ }^{2}$ \\ 1 IDL-Faculdade de Ciências da Universidade de Lisboa, Campo Grande, Ed. C8, 1749-016 Lisboa, Portugal; \\ fasantos@fc.ul.pt \\ 2 Laboratório Nacional de Energia e Geologia, Apartado 7586-Alfragide, 2710-966 Amadora, Portugal; \\ patricia.represas@lneg.pt \\ * Correspondence: fasantos@fc.ul.pt
}

\begin{abstract}
This work describes a method to carry out 2-D inversion of gravity data in terms of porosity and matrix density distribution using previous DC resistivity inversion results to constraint the fractional pore-water content in the rocks. The inversion is carried out using a controlled random search (CRS) algorithm for global optimization. The method was tested on synthetic data generated from a model representing a graben, and the results show that it can estimate accurate values of contrast-density and porosity. The method was also applied to gravity and dc experimental data collected in NE Portugal, showing results that agree quite well with the known geological information.
\end{abstract}

Keywords: porosity prediction; pore-water prediction; gravity; resistivity; combined inversion

\section{Introduction}

Porosity is an important parameter in earth sciences related to fluid flow and reservoir characterisation. It affects several rock physical parameters like density, acoustic impedance, seismic wave velocity and electrical resistivity.

Traditional methods to evaluate porosity are usually invasive, requiring rock sampling in wells. These methods only given localized results and may not be representative of the soil properties at regional scales. Non-invasive and low-cost geophysical methods represent alternative techniques to evaluate and characterize rock physical properties at large scales.

Gravity measurements are broadly used to investigate the structure of sedimentary basins (e.g., [1]). However, even though density of porous (or fractured) rocks is a function of porosity and of water in pore space, it is not possible to determine these parameters using only gravity data. Electromagnetic methods (with particular emphasis on dc resistivity) are frequently used to estimate those parameters in sedimentary formations [2, 3 and 4]. Gravity and resistivity measurements are related to each other through the porosity and water content. Therefore, a combined approach using both methods should provide a more accurate estimate of those parameters.

In this work, a method for inverting gravity data acquired in porous media using dc resistivity results to constraint the fractional pore-water content, is presented. The method 
seeks a solution for the inverse problem in terms of the rock-matrix density, porosity, and water-content of the geological formation. The method, which is not a joint inversion procedure, can be considered a cooperative inversion of two coincident geophysical data sets.

\section{Materials and Methods}

Bulk density $\sigma_{e}$ and fractional porosity $\phi$, for porous media partially filled with water, are related by the volume weighted density expressed by:

$$
\sigma_{e}=(1-\phi) \sigma_{m}+S_{w} \phi \sigma_{w}
$$

where $\sigma_{\mathrm{m}}$ is the rock matrix density and $\sigma_{\mathrm{w}}$ the pore-water density, and $S_{\mathrm{w}}$ is the fractional amount of saturation of pore water. The effect of the air in the pores is not considered in this equation.

Archie's law has been currently used for porosity assessment from resistivity (geoelectromagnetic) surveys carried out either on earth surface or in boreholes. For claycleaned rocks and low-frequency or dc methods, the Archie's law is expressed by [5],

$$
\rho_{\mathrm{e}} \quad=a \rho_{\mathrm{w}} \mathrm{S}_{\mathrm{w}}^{-n} \phi^{-m}
$$

where $a, n$ and $m$ are empirical constants, $\rho_{\mathrm{w}}$ and $\rho_{\mathrm{e}}$ are the water and the bulk resistivity, respectively, and $S_{w}$ is the fractional amount of saturation of pore space. Values between 0.6 to 1.0 for $a$ and, of 2.0 for $m$ and $n$ are commonly used for clay-free sandstones.

The gravity data was inverted using the controlled random search (CRS) algorithm for global optimization (see, e.g., [6]). This algorithm produces a random sample of the objective function hypersurface in the parameter space [6]). All sampled points of the parameter space that produce objective functions smaller than a threshold value, which is a function mainly of the data misfit, are saved and used in a statistical analysis. The mean of all sampled models is then taken as the best parameter estimation.

The CRS algorithm is fully described in the literature (e.g., [6]) and, for this reason, only the relevant points of our implementation will be described. Let $\mathbf{g}(\mathbf{r})$ be the $\mathrm{N}$ dimensional vector of gravity observations (Bouguer anomaly) and the theoretical 2-D gravity model responses be represented by $\mathbf{f}(\mathbf{r}, \mathbf{m})$. The vector $\mathbf{r}$ defines the position of the gravity measurements and $\mathbf{m}$ is the $\mathrm{M}$-dimensional vector of model parameters, i.e. the porosity $\phi$ and the matrix density $\sigma_{\mathrm{m}}$. To calculate theoretical responses, the region containing the gravitational sources is divided into $\mathrm{M}$ cells (Figure 1), consisting of rectangular blocks in the 2-D approach (see [7]). The computed gravity anomaly is then,

$$
\mathbf{f}(\mathbf{r}, \mathbf{m})=\mathbf{A}\left(\sigma_{e}-\sigma_{b}\right)
$$


where $\mathbf{A}$ is the gravitational attraction matrix, $\sigma_{b}$ is the background density, and $\left(\sigma_{e}-\sigma_{b}\right)$ is the vector containing the model density-contrast values. The element $\mathrm{A}_{\mathrm{ij}}$ of this matrix A represents the gravitational attraction at the point $\mathbf{r}_{\mathbf{i}}$ due to cell $\mathbf{j}$ having unit density.

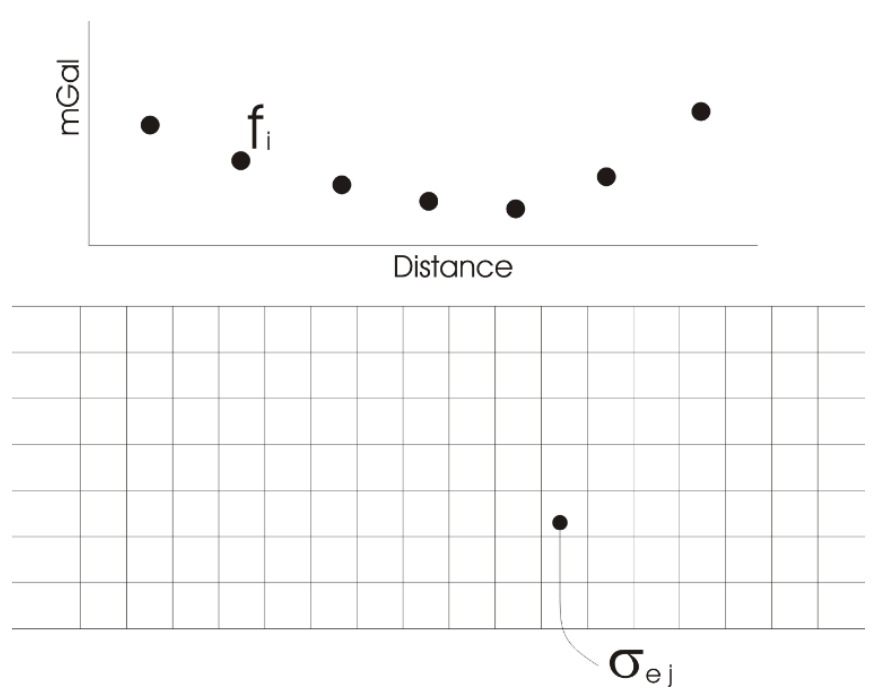

Figure 1. Vertical cross-section of the mesh used in 2-D gravity modelling. $\sigma_{\text {ej }}$ represents the bulk density of the block j.

The inversion problem consists of finding an estimate of the model parameters $\mathbf{m}^{*}$ such that the objective function is defined by

$$
\frac{1}{N}\left\{\sum_{i=1}^{N}\left[\left(g_{i}-f_{i}\right) / g_{i}\right]^{2}\right\}^{1 / 2}<\varepsilon
$$

subject to

$\mathbf{m}_{\mathrm{u}} \geq \mathbf{m}^{*} \geq \mathbf{m}_{\mathbf{l}}$,

where $\varepsilon$ is a quantity depending of the observational errors, $\mathbf{m}_{\mathbf{u}}$ and $\mathbf{m}_{\mathbf{l}}$ representing upper and lower a priori bounds of parameters. These bounds can be estimated from previous geological and/or geophysical results.

The algorithm starts by generating L models, each made up of M cells (or blocks). The matrix density and the porosity are randomly generated to construct each of these models. For each model, the $S_{w}$ is calculated from the dc resistivity model and porosity values using the Archie's law. The objective function is evaluated and the model with the largest objective function value is determined. In the second step of the algorithm, $(\mathrm{M}+1)$ models are randomly chosen among the L currently available, and the centroid of the first $\mathrm{M}$ chosen models is used to estimate the parameters (porosity and matrix density) of a new model, according to the vector equation, 
$\mathbf{m}=2 \mathbf{c}-\mathbf{q}$.

the vector $\mathbf{q}$ contains the parameters of the $(M+1)$ th chosen model and $\mathbf{c}$ is the vector with the centroid model parameters. The degree of water saturation is always determined from the resistivity model. Provided that the parameters of the model $\mathbf{m}$ satisfy the constraints expressed by condition (4), the objective function of the new model is evaluated and compared with those of the L current models. If the objective function of the new model is smaller than the greatest one in the L models, the new model is accepted and replaces the one with the greatest value of the objective function. The iterative process stops when all $\mathrm{L}$ models have objective function values smaller than a specified value $\varepsilon$.

\section{Ambiguity and sensitivity analysis}

The density-contrast $(\Delta \sigma)$ of a block in the model can be expressed by,

$$
\Delta \sigma=\sigma_{\mathrm{e}}-\sigma_{\mathrm{b}}=(1-\phi) \sigma_{\mathrm{m}}+\left[a \rho_{\mathrm{w}} /\left(\rho_{\mathrm{e}} \phi^{m-n}\right)\right]^{1 / n} \sigma_{\mathrm{w}}-\sigma_{\mathrm{b}}
$$

According to (3), the contribution of each block to the calculated gravity anomaly depends on the respective density-contrast. It is then possible to have several models with different combinations of porosity and matrix density that fit the data equally well. This assertion is the expression of the known problem of nonunique solution in gravity inversion. If $n=m$, a frequently adopted condition, equation (6) simplifies,

$$
\left.\Delta \sigma=\sigma_{\mathrm{e}}-\sigma_{\mathrm{b}}=(1-\phi) \sigma_{\mathrm{m}}+\left[a \rho_{\mathrm{w}} / \rho_{\mathrm{e}}\right)\right]^{1 / n} \sigma_{\mathrm{w}}-\sigma_{\mathrm{b}}
$$

This equation shows that, in these conditions, it is possible to decrease the ambiguity limiting the values of $\sigma_{\mathrm{m}}$.



a)

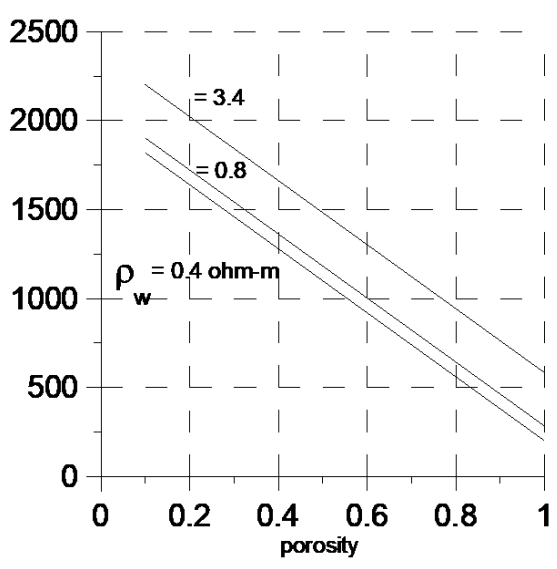

b)

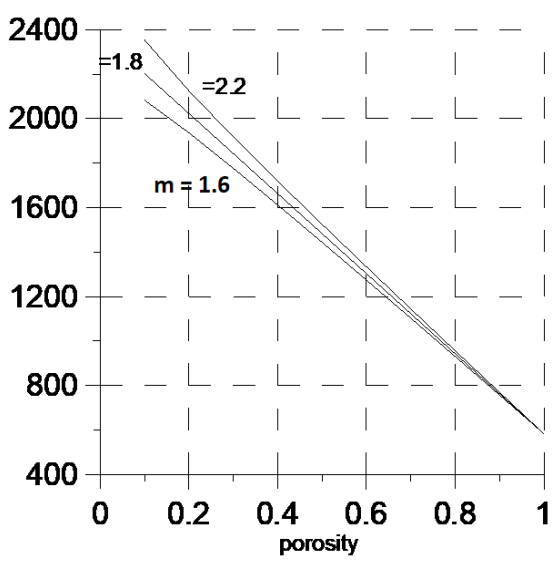

c)

Figure 2. Variation with porosity of bulk-density having $a, \rho_{\mathrm{w}}$ and $m$ as parameters. 
Parameters $a, \rho_{\mathrm{w}}, m$ and $n$ are chosen empirically at the beginning of the inversion. So, it is important to understand their influence in the solution, which affects the bulk density values. The variation of $\sigma_{\mathrm{e}}$ with $a$ and $\rho_{\mathrm{w}}$ depends on the value of $n$. However, the importance of the latter is very small (variations of $20 \%$ in the constant $n$ only produce changes in $\sigma_{e}$ of $0.01 \%$ ) and a linear dependence of $\sigma_{e}$ on $a$ and $\rho_{w}$ is observed. Figures 2a) and b) show the bulk density as a function of the porosity, having $a$ and $\rho_{\mathrm{w}}$ as parameters, respectively. The results presented in Figure 2 have been calculated assuming $\sigma_{\mathrm{m}}=1.8$ $\mathrm{g} / \mathrm{cm}^{3}, \sigma_{\mathrm{w}}=1 \mathrm{~g} / \mathrm{cm}^{3}, \rho_{\mathrm{e}}=3.4 \mathrm{ohm}-\mathrm{m}$ and $m=n=2$. From the figures it is possible to conclude that those parameters do not have a strong influence on the solution. In fact, variations of $30 \%$ and $50 \%$ in $a$ and $\rho_{\mathrm{w}}$, respectively, only produce changes of $5 \%$ in the bulk density. The dependence of the bulk density on the constant $m$ is shown in Figure 2c). A nonlinear dependence on the porosity can be noted in this case. The influence of $m$ is greater for small values of porosity. Nevertheless, it is possible to conclude that the influence of $m$, for the range of values usually adopted, is of the same order of the other analysed parameters. Hence, the final solution will depend mainly on the resistivity model used to constraint the saturation degree of the formations.

\section{Results}

\subsection{Synthetic data example}

The described method was firstly applied to gravity and dc-resistivity synthetic data generated from the model shown in Figure 3. Basically, the model simulates a 2-D graben (600 $\mathrm{m}$ wide and $437 \mathrm{~m}$ depth) filled with sedimentary rocks. The value of the different parameters (geometry, density, porosity, water content, electrical resistivity) used in the data generation are shown in Figure 3 and Table 1. The synthetic gravity data and dipoledipole apparent resistivity pseudosection are also presented in Figure 3. The residual gravity anomaly is characterized by a wide minimum over the graben, corresponding to the sedimentary filling. 

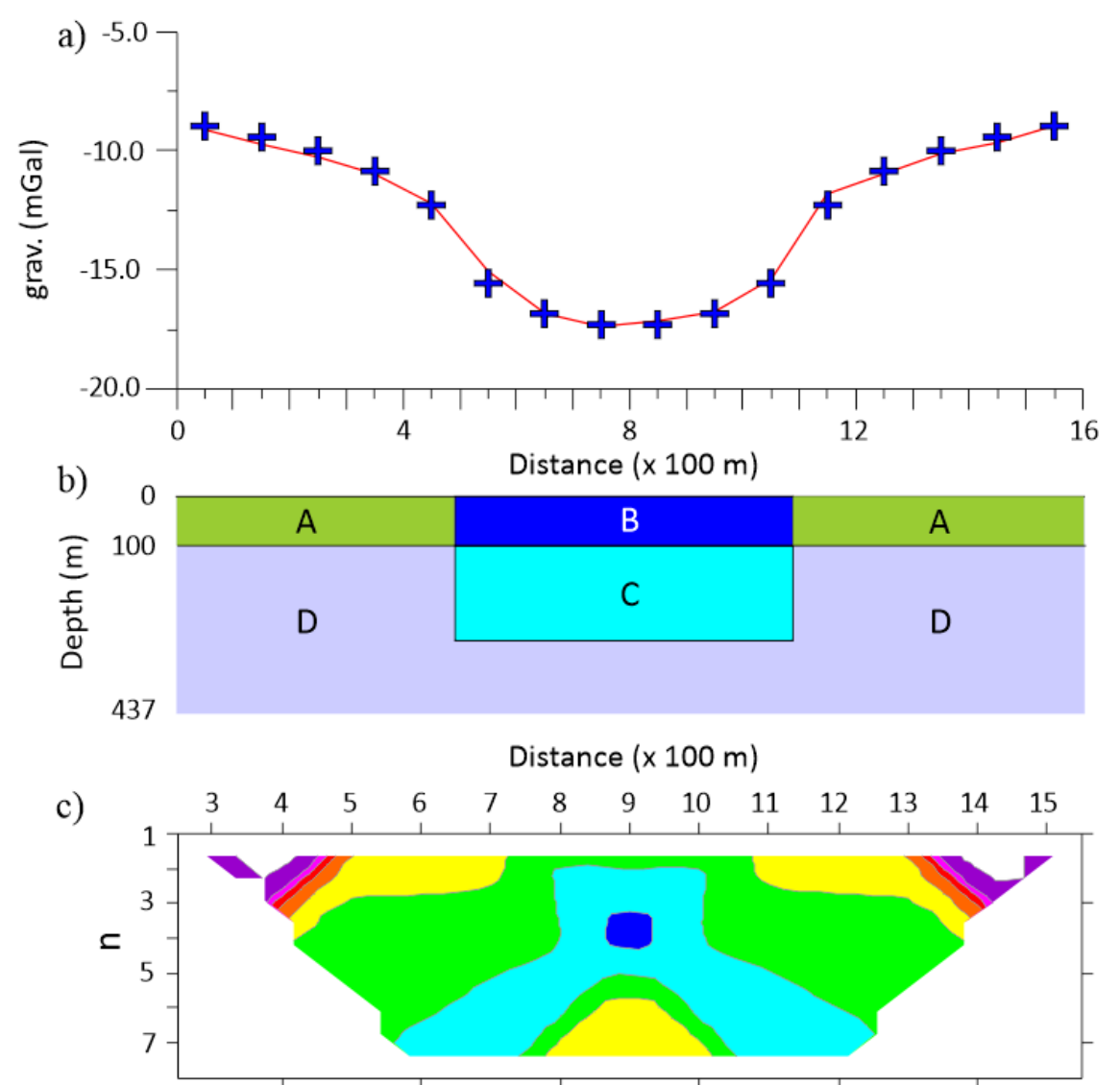

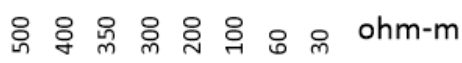

Figure 3. a) Gravity anomaly (symbols) calculated from the synthetic model shown in centre of the figure b). The parameter values are shown in Table 1. The solid line represents the response of the model shown in Figure 5a). c) Apparent resistivity pseudosection calculated from the same model (b) (dipole distance is $100 \mathrm{~m}$ ). Contours are in ohm-m.

Table 1. Parameterisation of the synthetic model shown in Figure 3.

\begin{tabular}{|c|c|c|c|c|}
\hline Parameter & A & B & $\mathrm{C}$ & $\mathrm{D}$ \\
\hline$\Delta \sigma \quad\left(\mathrm{kg} / \mathrm{m}^{3}\right)$ & -233 & -1158 & -810 & -165 \\
\hline$\phi \quad(\%)$ & 10 & 40 & 30 & 10 \\
\hline$\rho_{e}(\mathrm{ohm}-\mathrm{m})$ & 500 & 100 & 33 & 300 \\
\hline$S_{w} \quad(\%)$ & 77 & 43 & 100 & 100 \\
\hline
\end{tabular}

The dipole-dipole resistivity data was inverted separately to obtain a model of the electrical resistivity distribution (Figure 4) used to constraint the water saturation degree. The misfit of the final model is of $1 \%$. The presence of wet sediments is also revealed in the dipole-dipole data by the low resistivity zone (<60 ohm-m) depicted at depths greater than $100 \mathrm{~m}$. The combined gravity-resistivity inversion was performed with porosity values constrained in the 0.0 to 0.7 range. For the calculation of the saturation degree, a value 
of $3 \mathrm{ohm}-\mathrm{m}$ for the pore-water resistivity was assumed. The constant parameters in the Archie's law were set to $a=1.0$ and $n=m=2$. A value of $2650 \mathrm{~kg} / \mathrm{m}^{3}$ was assumed for the

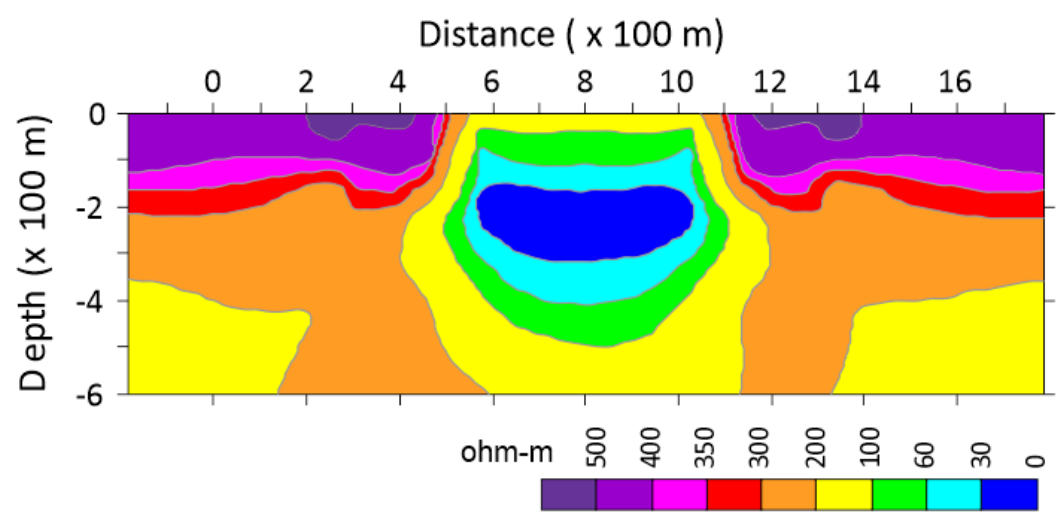

Figure 4. 2-D resistivity model corresponding to the inversion of the apparent resistivity data shown in Figure 3c. Contours are in ohm-m.

regional density, to calculate the contrast density. The matrix density was allowed to vary between 2000 and $3100 \mathrm{~kg} / \mathrm{m}^{3}$. It must be noted that the values of the water resistivity and regional density parameters are, in this case, equal to the "true" ones. Similar solutions have been obtained in experiments performed with different constraints on the matrix density ( 2000 to $\left.2900 \mathrm{~kg} / \mathrm{m}^{3}\right)$. An increase in the misfit of the model was observed narrowing the range of allowed matrix density values. The "best" range, in the sense that it produces the lowest misfit between data and model response, should be found experimentally.

Figure 5a) shows the density-contrast model obtained with the method described above. The correspondent gravity model response is shown in Figure 3 (solid line). The misfit between data and theoretical response is evaluated through the value of the objective function which, in this case, is $0.06 \%$. The sedimentary filling of the graben, assumed to be represented by the $-1000 \mathrm{~kg} / \mathrm{m}^{3}$ contour line, is clearly recognised in the model. The saturation degree distribution estimated during the inversion process is shown in Figure 5b). Except in the uppermost part of the graben, the saturation degree is greater than $70 \%$. The estimated porosity distribution shown in Figure 5c) is, in general, lesser than $20 \%$, except in the graben area where values greater than $30 \%$ have been estimated. 

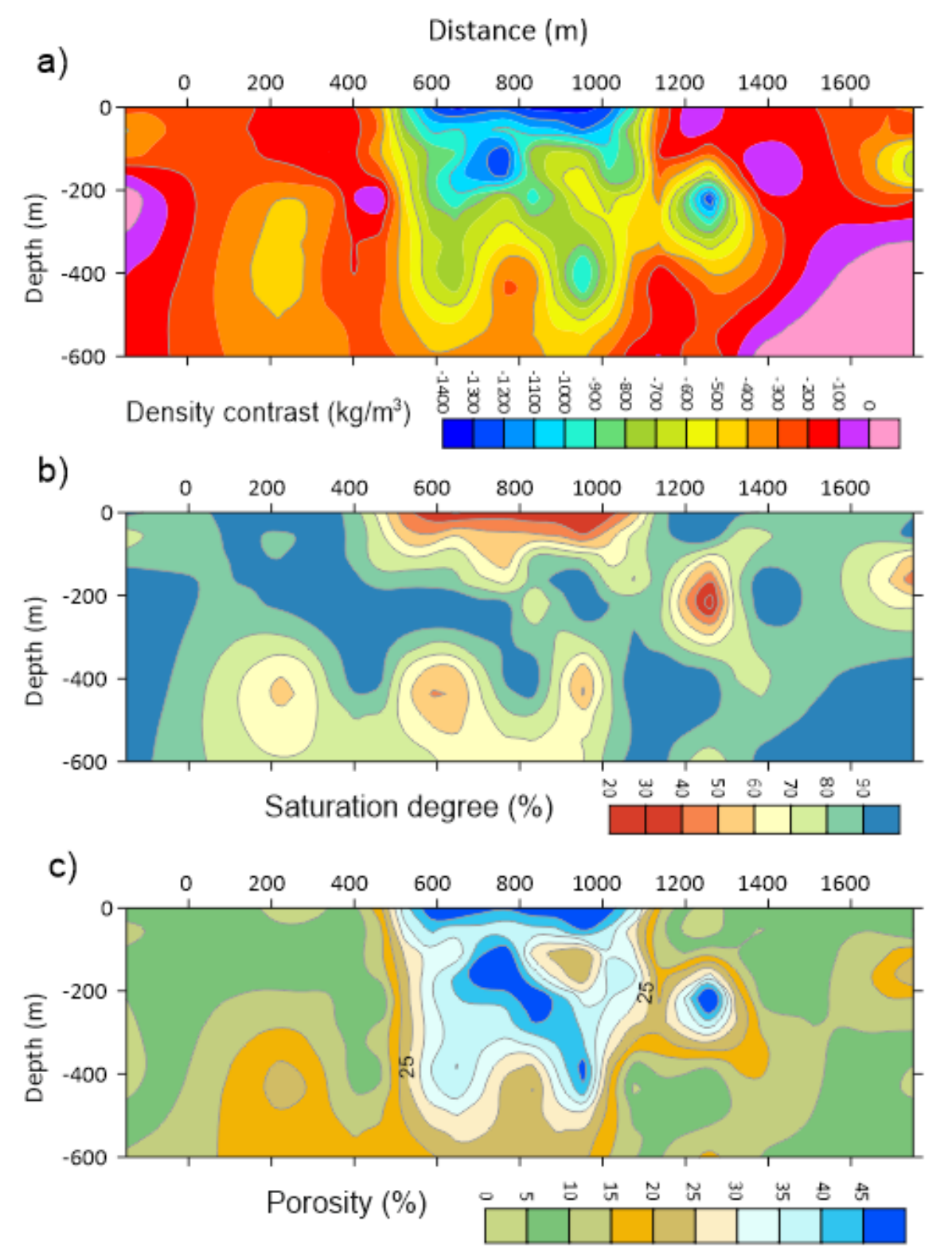

Figure 5. a) 2-D contrast-density model, b) 2-D pore-water distribution and 5c) 2-D porosity distribution obtained from the combined inversion of synthetic gravity and resistivity data using the method described in this work.

The results show that the estimated values of contrast-density, water saturation degree and porosity are within the expected range of values. The lateral dimension of the graben is well defined. The thickness of the anomalous body (a graben) is, however, not well determined. The weak resolution of the gravity data in such cases justifies the poor resolution in depth. It is also noted that the final inverted model does not present the perfect symmetry evidenced by the synthetic model. The random character of the CRS algorithm is, probably, responsible for this feature. 
Between 1990 and 1993, geophysical, geological, and geochemical research was performed in the Chaves region (NE Portugal) to construct the hydrothermal model associated with hot springs located close to Chaves city [8, 9 and 10]). The hot waters reach temperatures of $78^{\circ} \mathrm{C}$ and are known since Roman times. Morphologically the Chaves sedimentary basin (Quaternary), a graben striking in NNE-SSW direction that is bounded by granite (Hercynian) and metamorphic schistose formations (Figure 6a and b), dominates the region. The main fault controlling the structure is the NNE-SSW sinistral fault known as the Chaves-Verin fault.

a)
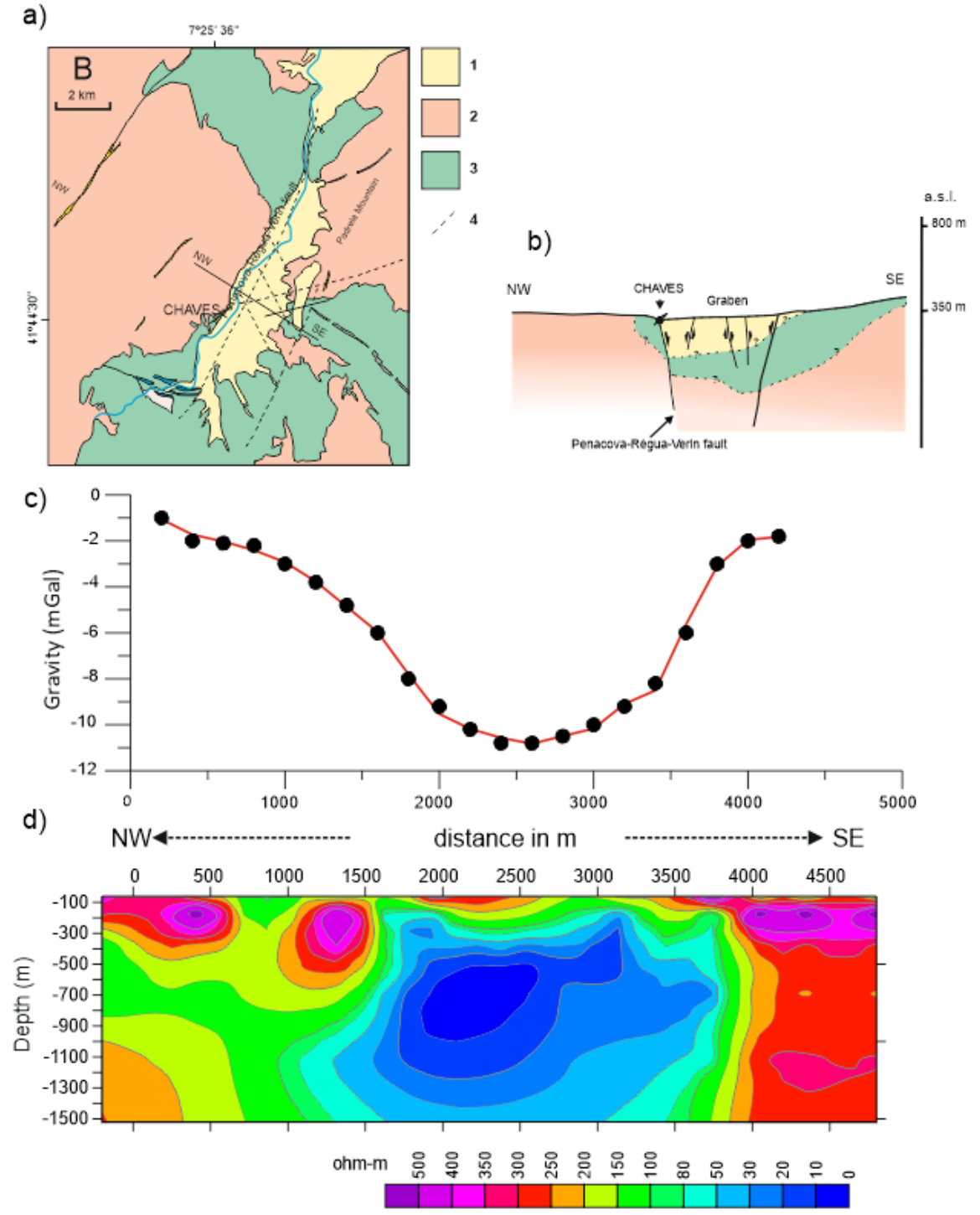

Figure 6 a). Geological sketch map of Chaves region; 1-sediments; 2 -granite; 3-schist; 4- normal fault. The line W-E represents the dipole-dipole and the gravity profiles; b) Geological cross-section along line W-E; c) Symbols- measured gravity anomaly. The solid line is the response of the model shown in Figure 7a); d) 2-D resistivity model obtained by inversion of apparent resistivity dipole-dipole data. Dipole distance is $300 \mathrm{~m}$. Contour lines are in ohm-m. 
Various geophysical methods, gravity, resistivity, self-potential audiomagnetotellurics and magnetotellurics, have been used to investigate the shallow and deep structures of the Chaves graben. The resistivity method was used to detect and define the geometry of the shallow water circulation within the graben. Figure $6 \mathrm{~d}$ ) shows a dipole-dipole resistivity model corresponding to a profile crossing the graben in the WNW-ESE direction (Figure 6a). This model was obtained from 2-D inversion of the field apparent resistivity data (not shown) using a regularization algorithm [11]). The main characteristic of the dipole-dipole model is the low resistivity zone $(<30 \mathrm{ohm}-\mathrm{m})$ depicted in its central part at depths greater than $300 \mathrm{~m}$. As a complement of the regional gravity survey, a gravity profile along the dipole-dipole profile was also carried out (Figure 6c). The residual gravity anomaly is characterized by a wide asymmetrical minimum over the graben, corresponding to its sedimentary filling.

The inversion was performed with porosity values constrained to the 0.0 to 0.7 range. The matrix density was allowed to vary between 2000 and $3100 \mathrm{~kg} / \mathrm{m}^{3}$. A value of $3.4 \mathrm{ohm}-$ $\mathrm{m}$ for the pore-water was used [12]) in the calculation of saturation degree. The constant parameters in the Archie's law were $a=1.0, n=m=2$. In the calculation of the contrast-density a value of $2650 \mathrm{~kg} / \mathrm{m}^{3}$ was assumed as regional density.

Figure 7a) shows the density-contrast distribution model obtained with the method described above. The correspondent model response is shown in Figure 6c). The misfit between data and theoretical response is evaluated through the value of the objective function, which is $0.99 \%$, in this case. A slightly different model (not shown) was obtained assuming a variation of the matrix density in the $2000-3000 \mathrm{~kg} / \mathrm{m}^{3}$ range. In the Figure $7 \mathrm{a}$ ) it is clearly recognised the sedimentary filling of the graben assumed to be represented by the $-300 \mathrm{~kg} / \mathrm{m}^{3}$ contour line. The density of the sediments, however, is not constant as it varies with depth because of the compaction of the sediments. 

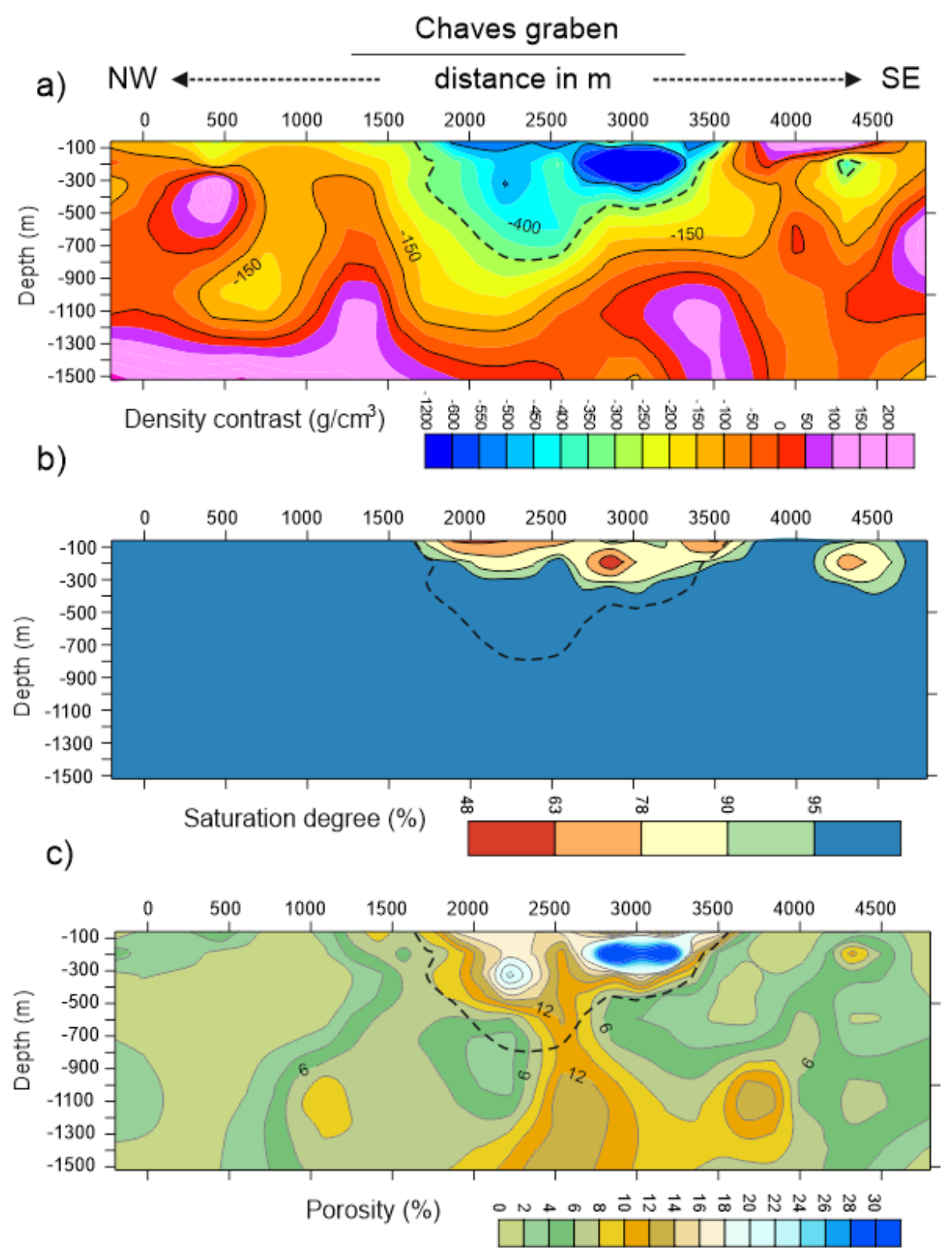

Figure 7 a) 2-D contrast-density model, b) 2-D pore-water distribution and c) 2-D porosity distribution obtained using the method described in this letter and the data set acquired in Chaves region.

The saturation degree distribution estimated during the inversion process is shown in Figure $7 \mathrm{~b}$ ). Except in the uppermost part of the graben the saturation degree is greater than $90 \%$. This is in accordance with the available information that suggests that the hydrothermal aquifer lies at a depth of $300 \mathrm{~m}$. The estimated porosity distribution shown in Figure 7c) is in general lesser than 6\%, except in the graben area where values greater than $10 \%$ have been estimated. Exceptionally, values greater than $45 \%$ appear in some parts of the graben. It is probable that such values are originated by a certain degree of overfitting of the gravity data together with inappropriate values of $\mathrm{n}$ and $\mathrm{m}$ parameters in Archie law. The most relevant feature in Figure 7c) is the area in the centre of the graben with porosity values of $10-12 \%$ that reach higher depths. The location of this relatively 
high porosity zone shows a strong correlation with the location of the Chaves-Verin fault and reveals the importance of this tectonic-structure in the hydrothermal circulation.

Similar porosity results were obtained from 2D joint inversion of dc and scalar AMT data acquired along the same profile [13]) and applying the Waxman and Smits [14] and the Sen's [15] models. The results suggested that the porosity of the reservoir (in the central part of the graben) is not uniform and might be in the range from $12 \%$ to $24 \%$.

\section{Discussion}

Prediction of porosity distribution from gravity inversion is feasible if resistivity data (from dc, transient or magnetotelluric surveys) are available to constraint the pore-water saturation. The use of Archie law is limited to free clay areas. However, clay is present in several environments. This can be taken into account using a modified Archie law. This study shows the importance of the $a, m$ and $n$ parameters. It is recommended to obtain experimental values for these parameters. The CRS method is easy to code and is fast enough to be used with advantages in the combined inversion here presented. The results obtained from a particular geological structure (a graben) suggest that the joint inversion of gravity and resistivity data might be a useful strategy in regional hydrological. However, further work is required to consider more general structures.

Author Contributions: Conceptualization, F.A.M.S. and P.R.; methodology, F.A.M.S. and P.R.; writing - review and editing, F.A.M.S. and P.R. All authors have read and agreed to the published version of the manuscript.

Funding: This research received no external funding.

Institutional Review Board Statement: Not applicable.

Informed Consent Statement: Not applicable.

Data Availability Statement: The data presented in this study are available on request from the corresponding author.

Acknowledgments: The authors gratefully acknowledge José Ribeiro and Mário Moreira for the gravity data. This work was supported by FCT under project UIDB/50019/2020 - IDL.

Conflicts of Interest: The authors declare no conflict of interest.

\section{References}

1. Chakravarthi, V., B. Ramamma, and T. V. Reddy, 2013, Gravity anomaly modeling of sedimentary basins by means of multiple structures and exponential density contrast-depth variations: A space domain approach: Journal of the Geological Society of India, 82, 561.

2. Cooper Y.L., Macnae J. and Tweed S. 2008. Estimating subsurface porosity and salt loads using airborne geophysical data. Near Surface Geophysics 6, 31-37.

3. Mota, R. and Monteiro Santos, F.A., 2010. 2D sections of porosity and water saturation from integrated resistivity and seismic surveys. Near Surface Geophysics, 2010, 8, 575-584.

4. Binley, A. and Kemna, A., 2005. DC Resistivity and Induced Polarization Methods. Hydrogeophysics, Y. Rubin and S. S. Hubbard (eds.), Hydrogeophysics, 129-156.

5. Grant, F.S. and West, G.F., 1965. Interpretation Theory in Applied Geophysics. McGraw-Hill Book Company.

6. Silva, J.B.C. and Hohmann, G.W., 1983. Nonlinear magnetic inversion using a random search method. Geophysics, 48, $1645-1658$. 
7. Telford, W.M., Geldart, L.P., Sheriff, R.E. and Keys, D.A., 1978. Applied Geophysics. Cambridge University Press, Cambridge, $860 \mathrm{p}$.

8. Monteiro Santos, F.A., Dupis, A., Andrade Afonso, A.R e Mendes Victor, L.A., 1996. An audio-magnetotelluric survey over the Chaves geothermal field (NE Portugal). Geothermics, 25 (3), 389-406.

9. Monteiro Santos, F. A., Andrade Afonso, A.R. and L. A. Mendes-Victor, 1997. Study of the Chaves geothermal field using 3D resistivity modeling. Journal of Applied Geophysics, 37, 85-102.

10. Monteiro Santos, F.A., Dupis, A., Andrade Afonso, A.R e Mendes Victor, L.A., 1999. Three-Dimensional modeling of a magnetotelluric survey over Chaves graben in northeast Portugal. In 3-D Electromagnetic Methods (Oristaglio, M. and Spies, B. Ed.), Society of Exploration Geophysicists, USA, 387-405.

11. Sasaki, Y., 1989: Two-dimensional joint inversion of magnetotelluric and dipole-dipole resistivity data. Geophysics, 54, 254-262.

12. Marques, J.M., Monteiro Santos, F.A., Graça, R.C., Castro, R., Aires-Barros, L. and Mendes Victor, L.A., 2001. A geochemical and geophysical approach to derive a conceptual circulation model of CO2-rich mineral waters: a case study of Vilarelho da Raia, Northern Portugal. Hydrogeology Journal, 9, 584-596.

13. Monteiro Santos, F. A., Andrade Afonso, A.R. and Dupis, A., 2007. 2D joint inversion of dc and scalar audio-magnetotelluric data in the evaluation of low enthalpy geothermal fields, Journal of Geophysics and Engineering, Volume 4, Issue 1, 53-62.

14. Waxman M H and Smits L J M 1968 Electrical conductivities in oil-bearing shaly sands Soc. Pet. Eng. J. 8 107-22.

15. Sen P N, Goode P A and Sibbit A 1988 Electrical conduction in clay bearing sandstones at low and high salinities J. Appl. Phys. 63 4832-40. 